no visible diffusion of solute into the continuous phase for drops containing up to 10 per cent solute.

$$
\begin{aligned}
& \text { F. H. Garner } \\
& \text { C. W. NUTT } \\
& \text { M. F. MoHtadi }
\end{aligned}
$$

Department of Chemical Engineering,

University of Birmingham. Dec. 10.

${ }^{1}$ Nature, 171, 1155 (1953).

\section{Age of Uraninites from Crystallographic Data}

Is a recent communication, Wasserstein ${ }^{1}$ has suggested a new method of age determinations on uraninites by means of X-ray techniques. This thesis is that radioactive decay results in the replacement of the tetravalent uranium ion by the smaller lead ion, the calculated shrinkage in cube edge due to this process being approximately $0.004 \mathrm{~A}$. per hundred million years. Wasserstein classifies uran inites into three groups : $\gamma\left(\mathrm{U}_{4} \mathrm{O}_{7}\right.$ type $), \alpha\left(\mathrm{UO}_{2}\right.$ type $)$ and $\beta\left(\mathrm{U}_{3} \mathrm{O}_{7}\right.$ type $)$, and suggests that thorianites, which resemble $\gamma$-uraninites in their properties, may have $\mathrm{Th}_{4} \mathrm{O}_{7}$ as their prototype.

We are of the opinion that this picture has been over-simplified and is not consistent with the known chemistry of the uranium oxides. In addition to the radioactive decay which tends to shrink the cube edge below that of pure uranium oxide, and the presence of thoria which serves to expand the lattice parameters, several other factors should be taken into consideration. Specifically these are : oxidation due to weathering, and radiation damage. As Wasserstein points out, oxidation of $\mathrm{UO}_{2}$ to $\beta-\mathrm{UO}_{2}$ results in $\mathrm{a}_{\mathrm{b}}$ decrease in cube edge from $5 \cdot 470 \mathrm{~A}$. to $5 \cdot 440 \mathrm{~A}$. Every uraninite specimen for which an analysis has been reported has been shown to be oxidized to some extent; some are altered sufficiently so that ignition in vacuum or an inert atmosphere converts them partially or even completely to $\mathrm{U}_{3} \mathrm{O}_{8}$, and this oxidation should be reflected in the lattice parameter. In this regard, Wasserstein's classification of $\gamma$-uraninites as $\mathrm{U}_{4} \mathrm{O}_{7}$ types is questionable. The existence of $\mathrm{U}_{4} \mathrm{O}_{7}$ itself is based only on $\mathrm{X}$-ray evidence $^{2}$ (an increase in cube edge above that of $\mathrm{UO}_{2}$ ), and has as yet not been substantiated by chemical analyses. Assuming that $\mathrm{U}_{4} \mathrm{O}_{7}$ actually has been prepared, which is doubtful, the method of preparation in each case has involved extreme reduc. ing conditions (that is, ignitions of mixtures of uranium oxide with uranium metal) which are not likely to be encountered in Nature. Extrapolation of this line of reasoning to suggest the existence of $\mathrm{Th}_{4} \mathrm{O}_{7}$ is, we believe, on even more doubtful ground since no experimental evidence exists for such a compound. Rather this phenomenon (contraction of the cube edge on ignition) in thorianite should suggest seeking an alternative explanation. It has been shown that radiation damage in a number of substances, including zircon, diamond, silicon carbide and quartz, results in an increase in lattice dimensions ${ }^{3}$. It would seem more reasonable to us to ascribe the $\gamma$-type ores to radiation damage than to reduction of uranium and thorium below the tetravalent state.

To the list of factors influencing lattice dimensions in uraninites should also be added the presence of rare-earth and alkaline-earth oxides, since these have been shown to form ternary fluorite-type oxides with uranium over a considerable oxygen to metal ion ratio range ${ }^{4}$.

We feel that all these factors will play a sig. nificant part in determining uraninite lattice dimensions, thus making an age-calculation based on Wasserstein's proposal of doubtful value.

HENRy R. HoEkstra

JOSEPH J. KATZ

Chemistry Division,

Argonne National Laboratory, Lemont, Illinois.

2 Wasserstein, B., Nature, 174, 1004 (1954).

${ }^{2}$ Zachariasen, W., MP Chicago Report $N-1973$ (1945). Rundle, R. E., et al., J. Amer. Chem. Soc., 70, 103 (1948). Hering, H., and Perio, P., Buli. Soc. Chem. France, 352 (1952).

s Hurley, P. M., and Fairbairn, H. W., Bull. Geol. Soc. Amer., 64, 660 (1953). Primak, W., et al., Phys. Rev., 92, 1064 (1953).

"See, Seaborg, G. T., and Katz, J. J., "The Actinide Elements", NNES, Div. IV, i4 A, 144, 175 .

THE criticism offered by Drs. Hoekstra and Katz is relevant in stressing certain chemical difficulties which may defy solution by conventional analyses-mineral chemists know such problems too well, for example, the role of iron in many minerals. They rely on chemical analyses of uraninites for their views; but I am suspicious of such analyses as they still report lead as $\mathrm{PbO}$, when that of radiogenic origin should be $\mathrm{PbO}_{2}$; that due to, say, galena, would be correctly given as $\mathrm{PbO}$. Such duality exists in the position of oxygen, too, as it takes a double role crystallographically in many uraninites-such data cannot adequately be determined chemically.

There must be grave doubts that the proportion of different uranium oxides, such as $\mathrm{UO}_{3}$ and $\mathrm{U}_{8} \mathrm{O}_{8}$, are in fact present as such in uraninites. Controversy is still rife among chemists in this very field of uranium oxides. How then can Drs. Hoekstra and Katz state that my thesis ". . . is not consistent with the known chemistry of the uranium oxides"? The operative word is, I suggest, "known". I agree that, in the interests of clarity, I have simplified my concepts, but I trust I have not done this to a fault.

The essential points of the criticism, which carried no surprises, can be answered as follows :

(1) Existence of $\mathrm{U}_{4} \mathrm{O}_{7}$ and $\mathrm{Th}_{4} \mathrm{O}_{7}$. Actually these compounds are not essential for my thesis. At this stage it may be advisable to write $\gamma$-uraninite as $\mathrm{UO}_{3-x}$. As experimental evidence indicates that oxidation is necessary to obtain the cube-edge of the corresponding $\alpha$-type from the $\gamma$-type, an analogue of a lower oxide than $\mathrm{UO}_{2}$ exists: Zachariasen's $\mathrm{U}_{4} \mathrm{O}_{7}$ is the closest laboratory counterpart. That the laboratory method of its preparation does not duplicate the conditions under which $\gamma$-type is formed in Nature is no criterion for the belief in the existence of the mineral or not.

All $\gamma$-uraninites are characterized by the presence of the large thorium ion ; pitchblendes carry virtually none of it, but may contain such small ions as those of zirconium and titanium (for example, in Colorado). These replacements of uranium are in accordance with the principle that lower valence of an element is indicative of larger ionic size, and conversely. The different 'valencies' envisaged in my classification must have influenced the nature of the replacements at the time of the formation of the minerals. Such observations stress the individuality of the $\gamma$-type.

The fact that $\mathrm{Th}_{4} \mathrm{~S}_{7}$ is known suggests that $\mathrm{Th}_{4} \mathrm{O}_{2}$ is possible; my statement that " $\mathrm{U}_{4} \mathrm{O}_{7}$ may be a separate compound analogous to $\mathrm{Th}_{4} \mathrm{~S}_{7}$ " was a 